\title{
ANALISIS BUTIR SOAL UJIAN AKHIR SEMESTER MATA KULIAH MAPEL SD MATEMATIKA I TAHUN AKADEMIK 2018/2019
}

\author{
Oleh \\ I Komang Wisnu Budi Wijaya; Ni Wayan Sri Darmayanti \\ wisnu.budiwijaya240191@gmail.com; wyndarmayanti@gmail.com \\ Institut Hindu Dharma Negeri Denpasar Indonesia; Universitas Muhamaddiyah \\ Mataram, NTB, Indonesia
}

diterima 2 Agustus 2019, direvisi 15 September 2019, diterbitkan 1 Oktober 2019

\begin{abstract}
Abstrak
Penelitian ini bertujuan untuk menganalisis butir soal ujian akhir semester mata kuliah Mapel SD Matematika 1 berdasarkan aspek validitas, reliabilitas, indeks kesukaran butir dan daya pembeda. Penelitian ini tergolong dalam penelitian deskriptif. Populasi dari penelitian ini adalah lembar jawaban mahasiswa peserta ujian akhir semester mata kuliah Mapel SD Matematika 1. Teknik sampling yang digunakan adalah teknik sampling jenuh. Data penelitian dianalisis secara deskriptif. Hasil penelitiannya adalah sebagai berikut : 1) setiap butir soal ujian akhir semester mata kuliah Mapel SD Matematika 1 memiliki harga validitas pada kisaran 0,300 0,700 dan tergolong tinggi, 2) harga reliabilitas sebesar 0,897 dan tergolong tinggi, 3) indeks kesukaran butir pada setiap soal berada pada interval $0,300-0,700$ dan tergolong sedang dan 4) daya pembeda butir soal nomor 1 dan 3 tergolong cukup sedangkan butir soal nomor 2, 4 dan 5 tergolong baik.
\end{abstract}

Kata Kunci: analisis, butir, soal, ujian akhir semester, Mapel SD Matematika 1

\begin{abstract}
The aim of this research was to analyze the questions item of final exam semester on Mapel SD Matematika 1 subject based on validity, reliability, difficulty index and potential differentiator. This research was descriptive. The population of this research was the student's answer sheet on their final exam semester of Mapel SD Matematika 1 subject. The sampling technique use was saturation sampling. The data research was descriptive analyzed. The results of this research were : 1) Each question item of final exam semester of Mapel SD Matematika 1 subject had validity value between 0,300-0,700 and classified high, 2) Reliability value 0,897 and classified high, 3) Difficulty index of each question was on interval 0,300-0,700 and classified medium and 4) potential differentiator of question number 1 dan 3 were fair and number 2, 4 and 5 were good.
\end{abstract}

Keywords: analysis, item, question, final exam semester, Mapel SD Matematika 1 
ADI WIDYA: Jurnal Pendidikan Dasar

FAKULTAS DHARMA ACARYA

INSTITUT HINDU DHARMA NEGERI

DENPASAR
Volume. 4, Nomor 2 Oktober 2019

ISSN: 2685-8312 (online)

ISSN: 2527-5445 (cetak

http://ejournal.ihdn.ac.id/index.php/AW

\section{Pendahuluan}

Pada hakekatnya proses pembelajaran terdiri dari tiga tahap yaitu perencanaan, pelaksanaan dan evaluasi. Kegiatan perencanaan terdiri dari penyusunan tujuan pembelajaran dan cara mencapai tujuan tersebut sedangkan kegiatan pelaksanaan bertujuan untuk merealisasikan perencanaan pembelajaran yang telah disusun. Kegiatan evaluasi berfungsi untuk mengkaji kesesuaian antara perencanaan dan pelaksanaan sekaligus menganalisis kemampuan peserta didik untuk mencapai tujuan yang telah direncanakan.

Proses evaluasi memerlukan suatu alat atau instrumen. Salah satu instrumen evaluasi yang umum digunakan adalah tes. Tes merupakan instrumen evaluasi yang berbentuk soal yang harus diselesaikan oleh peserta didik dalam kurun waktu tertentu. Bentuk tes bermacam-macam ada yang berupa tes pilihan ganda, uraian singkat, esai, menjodohkan dan benar-salah. Setiap tes tersebut memiliki karakteristik tertentu serta kelebihan dan kekurangan masingmasing.

Kegiatan evaluasi akan berjalan maksimal jika instrumennya (tes) memiliki kualitas. Kualitas suatu tes dapat diukur melalui empat indikator yaitu validitas, reliabilitas, daya beda dan tingkat kesukaran. Validitas adalah kemampuan suatu tes untuk mengukur hal yang akan diukur secara tepat sedangkan reliabilitas adalah kemampuan suatu tes untuk memberikan hasil yang tetap (Sukiman, 2012).
Mata kuliah Mapel SD

Matematika I merupakan salah satu mata kuliah di jurusan Pendidikan Guru Sekolah Dasar Hindu (PGSDH) Fakultas Dharma Acarya Institut Hindu Dharma Negeri (IHDN) Denpasar. Mata kuliah ini dalam struktur kurikulum jurusan PGSDH termasuk dalam kelompok mata kuliah keahlian program studi dengan bobot 2 satuan kredit semester (sks) dan diberikan pada semester III. Mata kuliah tersebut bertujuan untuk memberikan pemahaman kepada mahasiswa jurusan PGSDH tentang konsep matematika di jenjang sekolah dasar serta cara mengajarkan konsep tersebut kepada siswa.

Mengingat pentingnya mata kuliah Mapel SD Matematika I maka perlu dilakukan evaluasi untuk mengetahui kemampuan mahasiswa mencapai tujuan mata kuliah yang diharapkan. Salah satu bentuk evaluasi yang dilakukan adalah berupa ujian akhir semester (UAS). Tes yang digunakan sebagai alat evaluasi di UAS berupa soal esai. Dengan demikian, peneliti tertarik untuk menganalisis kualitas butir soal UAS mata kuliah Mapel SD Matematika I sebagai bahan refleksi atas evaluasi yang telah dilakukan pada mata kuliah tersebut.

\section{PEMBAHASAN Hasil}

Hasil penelitian yang ditampilkan berupa hasil uji validitas, uji reliabilitas, uji indeks kesukaran butir soal dan uji daya pembeda. Hasil uji validitas disajikan dalam Tabel 1 sebagai berikut : 
Tabel 1. Hasil Uji Validitas

\begin{tabular}{|c|c|c|}
\hline No & Butir Soal & $\mathrm{r}_{\mathrm{xy}}$ \\
\hline 1 & Soal 1 & 0,698 \\
\hline 2 & Soal 2 & 0,723 \\
\hline 3 & Soal 3 & 0,726 \\
\hline 4 & Soal 4 & 0,697 \\
\hline 5 & Soal 5 & 0,721 \\
\hline
\end{tabular}

(Sumber : Hasil Analisis Peneliti, 2018)

Berdasarkan data pada Tabel 1 tersebut dapat dinyatakan bahwa harga validitas $\left(r_{x y}\right)$ untuk masing-masing butir soal berada di interval 0,600 0,800. Harga uji validitas pada rentang
0,60 - 0,80 tergolong tinggi (Arikunto, 2010).

Uji reliabilitas dilakukan dengan metode Alpha Cronbach. Hasil uji reliabilitasnya disajikan dalam Tabel 2.

Tabel 2. Hasil Uji Reliabilitas

\begin{tabular}{|c|c|}
\hline Cronbach's Alpha & Nof items \\
\hline 0,897 & 5 \\
\hline
\end{tabular}

(Sumber : Hasil Analisis Peneliti, 2018)

Suatu soal dikatakan memiliki reliabilitas tinggi jika harga $r_{11}$ lebih besar dari 0,700 (Sukiman, 2012). Berdasarkan data pada Tabel 2 terlihat bahwa harga uji Alpha Cronbach berada diatas 0,700 yang menandakan reliabilitas soal tersebut berada pada kriteria tinggi.

Hasil uji indeks kesukaran butir (IKB) dan uji daya pembeda masingmasing ditampilkan pada Tabel 3 dan Tabel 4

\section{Tabel 3. Hasil Uji Indeks Kesukaran Butir (IKB)}

\begin{tabular}{|c|c|c|}
\hline No & Butir Soal & IKB \\
\hline 1 & Soal 1 & 0,362 \\
\hline 2 & Soal 2 & 0,576 \\
\hline 3 & Soal 3 & 0,422 \\
\hline 4 & Soal 4 & 0,704 \\
\hline 5 & Soal 5 & 0,570 \\
\hline
\end{tabular}

(Sumber : Hasil Analisis Peneliti, 2018) 
ADI WIDYA: Jurnal Pendidikan Dasar

FAKULTAS DHARMA ACARYA

INSTITUT HINDU DHARMA NEGERI

DENPASAR
Volume. 4, Nomor 2 Oktober 2019

ISSN: 2685-8312 (online)

ISSN: 2527-5445 (cetak

http://ejournal.ihdn.ac.id/index.php/AW

Tabel 4. Hasil Uji Daya Pembeda Soal

\begin{tabular}{|c|c|c|}
\hline No & Butir Soal & Daya Pembeda \\
\hline 1 & Soal 1 & 0,22 \\
\hline 2 & Soal 2 & 0,53 \\
\hline 3 & Soal 3 & 0,32 \\
\hline 4 & Soal 4 & 0,40 \\
\hline 5 & Soal 5 & 0,50 \\
\hline
\end{tabular}

(Sumber : Hasil Analisis Peneliti, 2018)

Indeks kesukaran butir (IKB) dapat digolongkan menjadi tiga kriteria yaitu $0,00-0,30$ tergolong sukar ; 0,31 - 0,70 tergolong sedang dan $0,71-1,00$ tergolong mudah (Arifin, 2011). Dengan demikian, berdasarkan data pada Tabel 3 dapat disimpulkan bahwa pada soal nomor 1 , 2, 3 dan 5 memiliki harga IKB pada kisaran 0,31 - 0,70 yang berarti IKB tergolong sedang. Kemudian soal nomor 4 memiliki harga IKB di atas 0,70 yang menandakan IKB tergolong mudah.

Kemudian mengenai daya pembeda, butir soal nomor 1 dan 3 memiliki harga daya pembeda masingmasing 0,22 dan 0,32. Harga daya pembeda soal dapat dibagi menjadi lima kategori yaitu $<0,00$ tergolong negative ; $0,00-0,20$ tergolong buruk ; 0,21 - 0,40 tergolong cukup ; 0,41 0,70 tergolong baik dan $0,71-1,00$ tergolong sangat baik (Asrul, 2015). Berdasarkan hal tersebut, maka daya pembeda butir soal nomor 1 dan 3 tergolong cukup. Butir soal nomor 2, 4 dan 5 memiliki harga daya pembeda pada kisaran 0,41 - 0,70 dan tergolong baik.

\section{Pembahasan}

Soal Ujian Akhir Semester (UAS) Mapel SD Matematika 1 ini diberikan kepada mahasiswa jurusan
PGSDH semester III tahun akademik $2018 / 2019$. Soal ini terdiri dari 5 (lima) butir soal essay. Materi yang diujikan antara lain Persen, Pecahan, Perbandingan, Bilangan Berpangkat dan KPK serta FPB. Masing-masing butir soal dianalisis validitas, indeks kesukaran butir (IKB) serta daya pembeda. Terkait dengan uji reliabilitas dilakukan secara menyeluruh pada soal UAS tersebut.

Mengenai validitas, setelah dilakukan pengujian ternyata setiap butir soal UAS memiliki tingkat validitas tinggi dengan harga $r_{x y}>0,3$. Validitas tertinggi dimiliki oleh butir soal nomor 4 dan validitas terendah dimiliki oleh butir soal nomor 1 . Tingkat validitas sebuah soal berarti menyatakan sejauh mana kemampuan soal tersebut mengukur kemampuan yang ingin diukur oleh pembuat soal. Dengan demikian, dapat dinyatakan bahwa semua butir soal UAS tersebut memang mampu mengukur kemampuan yang ingin diukur. Kemampuan yang diukur tersebut telah dirumuskan dalam kisi-kisi soal. Soal nomor 1, kemampuan yang akan diukur adalah mahasiswa mampu mengoperasikan perkalian dan pembagian bilangan berpangkat. Dalam soal tersebut yang disajikan adalah sebuah sistem bilangan 
ADI WIDYA: Jurnal Pendidikan Dasar

FAKULTAS DHARMA ACARYA

INSTITUT HINDU DHARMA NEGERI

DENPASAR
Volume. 4, Nomor 2 Oktober 2019

ISSN: 2685-8312 (online)

ISSN: 2527-5445 (cetak

http://ejournal.ihdn.ac.id/index.php/AW berpangkat dan mahasiswa

diperintahkan untuk menyederhanakan

sistem bilangan berpangkat tersebut menjadi lebih sederhana melalui operasi perkalian dan pembagian.

Kemampuan yang ingin diukur pada butir soal nomor 2 (dua) adalah mahasiswa mampu mengaplikasikan konsep KPK dan FPB ke dalam kejadian pada kehidupan sehari-hari. Bentuk soal yang disajikan adalah berupa dua orang buruh dengan upah yang berbeda dan mahasiswa dituntut untuk menghitung frekuensi kerja buruh tersebut agar mereka menerima jumlah upah yang sama berdasarkan konsep KPK dan FPB. Berarti soal tersebut telah sesuai dengan kemampuan yang ingin diukur. Pada soal nomor 3 (tiga) kemampuan yang ingin diukur adalah membuktikan dua pecahan senilai. Deskripsi soal nomor 3 (tiga) adalah disajikan dua buah pecahan yang berbeda dan mahasiswa diharuskan membuktikan melalui rumus bahwa kedua pecahan tersebut adalah senilai.

Pada butir soal nomor 4 (empat), disajikan dua buah pecahan biasa dan desimal untuk diubah menjadi persen. Soal ini sudah sesuai dengan kemampuan yang diukur yaitu mahasiswa mampu mengkonversi pecahan biasa dan desimal menjadi persen. Pada butir soal nomor 5 (lima), kemampuan yang akan diukur adalah mengaplikasikan konsep perbandingan untuk menentukan besar sudut pada bangun datar segitiga. Soal pada nomor tersebut menyajikan sebuah perbandingan ketiga sudut pada sebuah segitiga dan mahasiswa diminta untuk menentukan besar sudut masing- masing pada segitiga itu. Dengan demikian dapat disimpulkan bahwa setiap butir soal UAS Mapel SD Matematika 1 memiliki validitas yang baik karena mampu mengukur kemampuan yang akan diukur.

Berdasarkan hasil pengujian dengan reliabilitas Alpha Cronbach, soal UAS Mapel SD Matematika 1 memiliki reliabilitas tinggi yaitu sebesar 0,897. Hal ini menandakan bahwa soal tersebut memiliki keajegan yang baik sebagai alat ukur kemampuan mahasiswa. Mahasiswa semester III PGSDH tahun akademik 2018/2019 memiliki kemampuan yang bervariasi dalam bidang matematika. Selain itu, soal ini diberikan kepada seluruh mahasiswa tanpa mempertimbangkan kemampuan mereka sehingga kedua kondisi tersebut layak sebagai data pendukung reliabilitas soal tersebut bernilai tinggi.

Mengenai indeks kesukaran butir (IKB), semua butir soal UAS memiliki harga IKB berkisar pada angka 0,31 0,70 yang menandakan setiap butir soal UAS memiliki tingkat kesukaran sedang. Jika dikaji berdasarkan taksonomi Bloom versi Anderson soal nomor satu tergolong soal pada butir nomor 1 dan 4 tergolong soal aplikasi serta soal butir nomor 2, 3 dan 5 tergolong soal analisis. Soal pada ranah pengetahuan dan pemahaman sebaiknya soal bertipe mudah, soal pada ranah aplikasi dan sintesis dan soal pada ranah evaluasi tergolong pada soal kategori sukar (Sudjana, 2010).

Terkait dengan daya pembeda, hasil uji daya beda menyatakan bahwa soal nomor 1 dan 3 memiliki 
ADI WIDYA: Jurnal Pendidikan Dasar

FAKULTAS DHARMA ACARYA

INSTITUT HINDU DHARMA NEGERI
Volume. 4, Nomor 2 Oktober 2019

ISSN: 2685-8312 (online)

ISSN: 2527-5445 (cetak

http://ejournal.ihdn.ac.id/index.php/AW kemampuan daya pembeda pada taraf cukup dan butir soal nomor 2, 4 dan 5 berada pada kategori baik. Dengan demikian dapat disimpulkan bahwa setiap butir soal UAS tersebut mampu membedakan mahasiswa yang menguasai materi UAS dan yang belum menguasai materi UAS. Jika dilakukan telaah pada setiap butir soalnya, pada soal nomor 1 menguji tentang kemampuan mengoperasikan perkalian dan pembagian bilangan berpangkat. Agar mahasiswa mampu menjawab soal tersebut dengan benar, maka mahasiswa harus menguasai konsep perkalian dan pembagian dan menentukan bilangan berpangkat yang bisa disederhanakan. Jika kemampuan tersebut tidak dimiliki maka mahasiswa akan kesulitan menjawab soal tersebut dengan benar.

Pada butir soal nomor 2 mahasiswa yang tidak menguasai konsep KPK dan FPB serta mengaplikasikannya dalam permasalahan sehari-hari akan kesulitan menjawab soal tersebut sebab soal tersebut menuntut penguasaan konsep KPK dan FPB. Kemampuan mahasiswa menggunakan rumus pecahan senilai sangat diperlukan untuk menjawab butir soal nomor 3. Begitu juga dengan butir soal nomor 4 yang menuntut kemampuan mahasiswa dalam mengkonversikan pecahan menjadi persen. Terakhir butir soal nomor 5 sangat membutuhkan kemampuan mahasiswa memahami konsep perbandingan, segitiga dan menganalisis besar sudut pada segitiga.

Setelah dilakukan analisis pada soal beserta butir soal maka peneliti melangkah pada tahap selanjutnya yaitu tindak lanjut. Peneliti menetapkan soal yang memenuhi tiga kriteria maka akan dipertahankan sebagai soal UAS di periode berikutnya, soal yang memenuhi dua kriteria akan dilakukan revisi dan soal yang hanya memenuhi satu kriteria saja atau sama sekali tidak memenuhi kriteria akan digugurkan. Adapun kriteria yang dimaksud adalah memiliki validitas pada level tinggi, IKB pada kriteria sedang dan daya pembeda minimal baik. Berdasarkan kriteria itu, maka butir soal nomor 1 dan 3 akan dilakukan revisi karena hanya memenuhi dua kriteria yaitu validitas tinggi dan IKB sedang namun daya pembeda masih berada pada kategori cukup. Butir soal nomor 2, 4 dan 5 telah memenuhi tiga kriteria sehingga layak dipertahankan.

Selain itu komposisi soal UAS Mapel SD Matematika 1 masih belum proporsional jika dikaji dari IKB. Suatu soal dikatakan proporsional jika komposisinya $30 \%$ soal mudah, $40 \%$ soal sedang dan $30 \%$ soal sukar (Sudjana, 2010). Namun pada soal UAS Mapel SD Matematika 1 komposisi soalnya adalah 100\% berupa soal sedang. Dengan demikian, dipandang perlu melakukan revisi soal baik secara kualitas dan kuantitas agar membentuk sebuah komposisi yang proporsional.

\section{SIMPULAN}

Berdasarkan uraian hasil penelitian dan pembahasan, dapat disimpulkan bahwa soal UAS Mapel SD Matematika 1 memiliki validitas dan reliabilitas tinggi. Kemudian indeks kesukaran butir (IKB) berada 
ADI WIDYA: Jurnal Pendidikan Dasar

FAKULTAS DHARMA ACARYA

INSTITUT HINDU DHARMA NEGERI

DENPASAR
Volume. 4, Nomor 2 Oktober 2019

ISSN: 2685-8312 (online)

ISSN: 2527-5445 (cetak

http://ejournal.ihdn.ac.id/index.php/AW pada kategori sedang. Mengenai daya pembeda, butir soal nomor 1 dan 3 berada pada kategori cukup dan butir soal nomor 2, 4 dan 5 berada pada kategori baik. Dengan demikian, soal UAS Mapel SD Matematika 1 layak digunakan sebagai instrumen evaluasi untuk mengukur pemahaman mahasiswa terhadap mata kuliah Mapel SD Matematika 1.

\section{DAFTAR PUSTAKA}

Arifin. (2011). Evaluasi

Pembelajaran. Bandung: PT.
Remaja Rosdakarya.

Arikunto. (2010). Dasar Dasar

Evaluasi Pendidikan. Jakarta:

Bumi Aksara.

Asrul. (2015). Buku Evaluasi

Pembelajaran. Bandung:

Citrapustaka Media.

Sudjana. (2010). Penilaian Hasil dan

Proses Belajar Mengajar.

Bandung: PT. Remaja

Rosdakarya.

Sukiman. (2012). Pengembangan

Sistem Evaluasi. Yogyakarta:

Insan Madani. 